\title{
Identity Development through Participation in an Informal Setting
}

\author{
Joseph L. Polman \\ University of Missouri-St. Louis, School of Education, 8001 Natural Bridge Rd, St. Louis, MO 63121-4899 \\ Tel: 314-516-7210, Fax: 314-516-5348 \\ Email: polman@umsl.edu
}

\begin{abstract}
Development among participants in learning environments is not limited to cognitive mastery, or "knowing how" and "knowing that." Rather, it often involves appropriation, a process of making ideas one's own, or part of one's identity. A case study of one child's development through participation in an after school club illustrates the benefits of considering both mastery and appropriation as important benchmarks of success.
\end{abstract}

Keywords: learning environments, informal learning environments, learning theory

\section{Introduction and Theoretical Background}

To the extent that educational and cognitive research examines learning, it tends to focus on cognitive mastery. An unfortunate consequence of this state of affairs is that research on learning has a tendency to ignore important aspects of the overall educational mission of many programs in the real world. In most educational endeavors, cognitive mastery is not the only sort of learning valued by leaders and participants. In particular, programs with less concrete and discrete curricular goals than formal schooling have a tendency to highly value aspects of learning that relate to identity formation and development.

Some recent concepts from the psychological and educational research community may prove useful for more broadly framing research on learning. In James Wertsch's (1998) sociocultural approach, he distinguishes between what he terms "mastery" and "appropriation." Mastery is characterized as traditional considerations of "knowing how to do" particular actions, whereas appropriation is characterized as "making something one's own." A failure of appropriation, described as "resistance," occurs when individuals distance themselves from actions, and only perform them under duress. An example is citizens in the former Soviet republic of Estonia, who mastered the "party line" historical accounts of their region's "socialist revolution," performed them flawlessly in public forums such as classes, but did not make this official history their own. Instead, they resisted it and denounced it in safer, more private settings. Thus we have an example of "mastery without appropriation."

Although researchers seldom attempt to distinguish between mastery and appropriation, instances such as the Estonian one where the two do not occur together are important. "Appropriation without mastery" may also occur, in which a learner becomes committed to an interest or way of thinking. An example of the latter is a child who visits a science museum, and returns from the trip fascinated with frogs - the child probably has not mastered a deep understanding of frogs' biology, but they may have "opened a new file folder" (Valenta, 1999) for that interest. Although the file folder may initially be empty, the folder may provide a placeholder leading to more traditional mastery over time. Along these lines, Bransford and Schwartz (1999) have pointed out that "preparation for future learning" is as important as, if not more important than, "accomplished learning." Transferring learning from one situation to another always involves an active process of learning something new about the differences and similarities between the familiar situation and the situation at hand-what they refer to as "knowing with" previous experience. In addition, learners must choose to apply learning from one situation to another, and forced school learning is notoriously seldom transferred to non-school problems even when relevant (Resnick, 1987).

\section{Method}

In this poster, I focus on the identity developmental aspects of learning in a voluntary after school history and computer club. The club was one of two directed by the author and staffed by undergraduate students from a nearby university. Participants at this location were five children aged 10 to 11 years old, all attending the school where the club met. The main goal of the club was to produce web pages related broadly to the history of resistance to slavery within the US, with particular attention paid to local Underground Railroad activity. Data sources included written field notes by the author and undergraduate students, videotapes of the club activity, interviews with the principal, and interviews with students. This analysis focuses on one child's participation. 


\section{Bobby's Case: Development from Being "Real Bad at" Social Studies to "Whiz"}

"Bobby" (a pseudonym) became involved in the after school club at the recommendation of his school principal. The principal felt that he and other fourth and fifth grade boys at the school would benefit from more male role models such as the undergraduates and club director. She hoped Bobby, who she characterized as "a good kid who had fallen in with a tough crowd" and begun to develop behavior and academic problems, would benefit from participation. She hoped "something positive to do with his time and energy" would get him back on track.

Bobby joined the after school club during the second semester of the 1997-98 school year, when he was in fourth grade. At that time, the participants in his club were guided in a "Jigsaw"-like (e.g., Cognition \& Technology Group at Vanderbilt, 1990) activity involving the construction of a web-based historical simulation. Each child and undergraduate mentor chose a topic related to the Underground Railroad, and built a set of linked computer screens which, when assembled, constituted an "online historical re-enactment" of escaping from slavery. Bobby and his mentor worked on "crossing rivers." After discussing their topic, they storyboarded their screens on index cards, and then built a complex set of branching pages having to do with decisions and consequences of various choices in various seasons. They included an event based on Harriet Beecher Stowe's account from Uncle Tom's Cabin about a young mother crossing the Ohio River in winter by jumping from ice floe to ice floe. After Bobby had created a number of pages, other children began to follow his model, and the "online historical re-enactment" was a success.

During the meetings of the after school club, Bobby's work was recognized and praised by the adults and the principal, and implicitly admired by both academically interested peers and members of the "tough crowd". He was further recognized by being chosen to represent his school at the unveiling of the African-American Civil War Memorial in Washington DC that summer. By the end of the following school year, Bobby had been able to develop an identity which enabled him to excel at academically oriented tasks, but also remain friendly with some members of the tough crowd. As he said, "I had a C in social studies [last] year and I was real bad at it, and now ... this year we already did all the stuff in social studies that we went over in the computer club, so I can whiz through and get A's and B's." Interestingly, the after school club "covered" little "factual content" from the school curriculum, and Bobby did not have the opportunity in the relatively few hours spent on historical analysis to master skills directly transferable to social studies class. What Bobby was clearly able to do was appropriate a positive stance toward social studies content. This positive stance, gained through his after school experiences, enabled Bobby to develop the identity of a "good social studies student," which combined with a greater sense of self-efficacy (Bandura, 1977) to drive greater mastery of school-based skills. He also appropriated and mastered computer skills, and led his family to upgrade and maintain a new computer connected to the Internet.

This case study serves to illustrate the importance and value of evaluating identity developmental aspects of learning, in addition to the sort of cognitive mastery usually considered in the learning sciences.

\section{References}

Bandura, A. (1977). Self-efficacy: Toward a unifying theory of behavioral change. Psychological Review, 84(2), 191-215.

Bransford, J. D., \& Schwartz, D. L. (1999). Rethinking transfer: A simple proposal with multiple implications. Review of Research in Education, Volume 24. A. Iran-Nejad, \& Pearson, P. D. Washington, DC: American Educational Research Association, (pp. 61-100).

Cognition \& Technology Group at Vanderbilt (1990). Anchored instruction and its relationship to situated cognition. Educational Researcher, 19 (6), 2-10.

Resnick, L. B. (1987). Learning in school and out. Educational Researcher, 16, 13-20.

Rogoff, B. (1994). Developing understanding of the idea of communities of learners. Mind, Culture, and Activity, 1(4), 209-229.

Valenta, C. (1999). Personal communication.

Wertsch, J. V. (1998). Mind as action. New York: Oxford University Press.

\section{Acknowledgments}

The research reported on here was supported by the James S. McDonnell Foundation. I wish to thank Jim Wertsch and Washington University for supporting the project, as well as the participating children, parents, and schools. 